\title{
The interplay of BMP4 and IL-7 regulates the apoptosis of intestinal intraepithelial lymphocytes under conditions of ischemia/reperfusion
}

\author{
BINYU LUO ${ }^{1,2}$, KANG CHEN ${ }^{2}$, QI FENG ${ }^{2}$, WEIDONG XIAO ${ }^{2}$, DAN MA ${ }^{2}$, HUA YANG $^{2}$ and CHAOJUN ZHANG ${ }^{2,3}$ \\ ${ }^{1}$ Department of General Surgery Two, Nanchong Central Hospital, The Second Clinical College of North Sichuan Medical University, \\ Nanchong, Sichuan 637000; ${ }^{2}$ Department of General Surgery, Xinqiao Hospital, The Third Military Medical University, \\ Chongqing 400037; ${ }^{3}$ Department of General Surgery, PLA Navy General Hospital, Beijing 100048, P.R. China
}

Received November 3, 2016; Accepted January 11, 2018

DOI: $10.3892 / \mathrm{ijmm} .2018 .3480$

\begin{abstract}
The number and function of intestinal intraepithelial lymphocytes (IELs) have been found to be significantly reduced following induction of acute intestinal mucosal damage via intestinal ischemia/reperfusion (I/R). However, the mechanism underlying this reduction remains unclear. Therefore, it was hypothesized that the interplay of bone morphogenetic protein (BMP)4 and interleukin (IL)-7 regulates IEL function and number. Recent studies have demonstrated that the different components of the BMP2/4 signaling pathway are expressed in intestinal epithelial cells (IECs) via the activation of nuclear factor $(\mathrm{NF})-\kappa \mathrm{B}$. In the present study, reverse transcription-polymerase chain reaction analysis and flow cytometry demonstrated that IELs express BMP receptors (BMPRIA, BMPRIB, ActRIA and BMPRII) and non-canonical signal transduction molecules $(\mathrm{NF}-\kappa \mathrm{B})$. An in vivo mouse intestinal $\mathrm{I} / \mathrm{R}$ model was used, and I/R was shown to increase the expression of BMP4 in IECs and upregulate the expression levels of BMPRIA, BMPRIB and phosphorylated NF- $\kappa$ B in IELs. Following isolation and culture of IELs, it was observed that exogenous BMP4 also upregulated the expression of BMPRIA and BMPRIB and activated $\mathrm{NF}-\kappa \mathrm{B}$ signaling in IELs, inducing IEL apoptosis. In addition, the rate of apoptosis of IELs decreased following treatment with the BMP-specific antagonist NOGGIN or with the NF- $\kappa \mathrm{B}$ inhibitor pyrrolidine dithiocarbamate. Furthermore, it was observed that exogenous IL-7 can decrease BMP4 protein expression in IECs and the expression of phosphorylated NF- $\kappa \mathrm{B}$ protein in IELs. The findings of the present study suggest that, under conditions of I/R, IEC-derived BMP4 activates NF- $\mathrm{BB}$ signaling in IELs, inducing IEL apoptosis, further aggravating the dysfunction of the intestinal mucosal barrier. However, these
\end{abstract}

Correspondence to: Dr Chaojun Zhang, Department of General Surgery, PLA Navy General Hospital, Beijing 100048, P.R. China E-mail: 1939618043@qq.com

Key words: ischemia/reperfusion, intestinal epithelial cells, intestinal intraepithelial lymphocytes, bone morphogenetic protein 4 , interleukin-7 effects may be alleviated by IL-7 treatment. Therefore, BMP4 and IL-7 appear to be involved in the interaction between IECs and IELs and in the mechanism underlying intestinal mucosal barrier dysfunction.

\section{Introduction}

Intestinal ischemia/reperfusion (I/R) injury is a common clinical event that occurs during surgery for abdominal aortic aneurysm, mesenteric artery occlusion, small bowel transplantation, cardiopulmonary bypass, strangulated hernias, trauma, and shock (1). Acute intestinal ischemia is a life-threatening emergency that is associated with substantial morbidity and mortality (2). However, the exact mechanism involved in the pathogenesis of acute intestinal ischemia has not yet been clearly defined. The intestinal mucosal barrier is a complex entity comprising different structural, mechanical, physical, immune, biological and chemical components, among others. Due to the presence of intestinal epithelial cells (IECs) and intestinal intraepithelial lymphocytes (IELs) in the intestinal mucosa, the epithelial layer is a key factor that determines the barrier function of the intestinal mucosa $(3,4)$. IELs mainly consist of $\mathrm{T}$ cells, which are interspersed among the IECs in the small intestine; there are 20 IELs for every 100 IECs in the small intestine (5). IELs play an important role in the maintenance of mucosal homeostasis, as they form the first line of immune defense against invasion, while they also preserve the integrity of the mucosal barrier (6). I/R-induced acute intestinal mucosal damage significantly promotes apoptosis of IELs and affects the phenotype and function of IELs (7). The immune function of IELs may be regulated by IECs. In order for the intestinal barrier to function properly, there must be communication between the IELs and the IECs, which is initiated through the activation of IECs by direct contact or through the effects of secreted factors on IELs, maintaining their growth and metabolism. However, the mechanism underlying this dialogue remains unclear (8).

Bone morphogenetic proteins (BMPs) play a pivotal role in the patterning and cellular fate of numerous tissues and organs, including the intestinal mucosal epithelium (9). Over 30 BMPs have been reported, and they all belong to the larger 
transforming growth factor (TGF)- $\beta$ family. BMP signaling includes the canonical Smad signaling pathway and the non-canonical mitogen-activated protein kinase and nuclear factor $(\mathrm{NF})-\kappa \mathrm{B}$ signaling pathways (10). BMPs are primarily found in epithelial cells (ECs) in the intestinal mucosal barrier. It was previously reported that the abundance of BMP2, BMP4 and $\mathrm{BMP}$ receptors at the protein level was greater in the total parenteral nutrition (TPN) group compared with that in the control (11). In addition, hypoxia and I/R were found to increase the expression of BMP2/4 and upregulated the expression of the BMP receptors BMPRIA and BMPRII in an in vivo mouse intestinal I/R model. I/R also activated the $\mathrm{NF}-\kappa \mathrm{B}$ signaling pathway, which led to increased levels of inflammatory factors, such as tumor necrosis factor (TNF)- $\alpha$ and interleukin (IL)-6; this in turn aggravated the damage to the intestinal mucosal barrier (12). Therefore, the expression of BMP4 was increased in the intestinal mucosal epithelial cells under simulated stress conditions. Moreover, BMP2/4 signaling is involved in thymocyte development (13), and it has been reported that it directly regulates fetal T-cell development through BMPRIA. Additionally, use of the specific BMP antagonist NOGGIN revealed that BMP2/4 signaling is a negative regulator of fetal T-cell development (14). BMP4 treatment of human-mouse fetal thymus organ culture resulted in a reduction in the recovery of human cells and the inhibition of $\mathrm{CD}^{+} 4^{+}$progenitor cell proliferation and differentiation (15). NF- $\kappa \mathrm{B}$ signaling proteins comprise a family of pleiotropic transcription factors that are involved in the embryonic development of various organs, inflammation, the immune response, cell survival, proliferation and differentiation (16). Additionally, it was determined that $\mathrm{NF}-\kappa \mathrm{B}$ is activated within a few hours after I/R, leading to upregulation of inflammatory proteins (17).

IL-7 is produced by stromal cell components in the bone marrow, thymus and in peripheral lymphoid compartments, and is a master regulator of T-cell development and homeostasis $(18,19)$. IL-7 binds to the IL-7R heterodimer, which is composed of the IL-7-specific IL-7R $\alpha$-chain (CD127) and the $\gamma$ c-chain (CD132). IL-7 induces CD127, which is linked to the activation of the Janus kinase/signal transducer and activator of transcription 5 (STAT5) signaling pathway. This pathway is crucial for cell survival and the upregulation of anti-apoptotic Bcl-2 proteins, which maintain T-cell homeostasis and prevent the progression of inflammation $(20,21)$. IL-7 signaling and the CD127 receptor were found to maintain the balance of regulatory $\mathrm{T}$ cells in vivo (22). In the intestine, IL-7 is produced by IECs and, in turn, IL-7 receptors (CD127 and CD132) have been detected on IELs (23). The IL-7/IL-7R signaling pathway plays a key role in the regulation of IELs (24), as IL-7 has been demonstrated to increase the numbers and functional capacity of IELs. It was previously demonstrated that TPN results in loss of IEC-derived IL-7, which leads to a marked weakening in the function and phenotype of IELs $(25,26)$. IL-7 produced in the thymus is also essential for the development of IELs (27). Therefore, IL-7/IL-7R signaling appears to be crucial for the maintenance of the function and growth of IELs.

It was reported that the interplay of BMP4 and IL-7 is key to the maintenance of the human thymic progenitor population. BMP4 downregulates the expression of CD127 in the precursor cell population, which leads to a reduction in the proliferation and differentiation of $\mathrm{CD} 34^{+}$progenitor cells. In addition, IL-7 stimulates the expansion and differentiation of intrathymic precursors $(13,15)$. Therefore, it was hypothesized that the interplay between BMP4 and IL-7 regulates the number and function of IELs following I/R. Our data indicated that IELs express functional BMP receptors. BMP proteins activate the NF- $\mathrm{NB}$ signaling pathway, which increases apoptosis, but they also inhibit apoptosis induced by IL-7/IL-7R signaling and maintain the number of IELs, indicating that the interplay between the BMP4 and IL-7 signaling pathways is important in the dialogue between IECs and IELs.

\section{Materials and methods}

Preparation oftest substances. Anti-p-NF-кB-PE(cat.no.9401S; 1:50) was purchased from Cell Signaling Technology, Inc. (Boston, MA, USA). Anti-CD45-APC (cat. no. MHCD4527; 1:200), anti-BMPRIA-FITC (cat. no. 11-7301-34; 1:150), anti-BMPRIB-FITC (cat. no. 11-6587-72; 1:150) and anti-CD127-Alexa Fluor 488 (cat. no. 53-1271-80; 1:100) were purchased from eBioscience (San Diego, CA, USA). The anti-GAPDH antibody (cat. no. 10494-1-AP; 1:5,000) was purchased from the ProteinTech Group, Inc. (Chicago, IL, USA), whereas anti-BMP4 (cat. no. sc-6267; 1:500), anti-IL7 (cat.no. sc-365306; 1:500) and anti-BMPRIA (cat.no. sc-293175; 1:200) were purchased from Santa Cruz Biotechnology, Inc. (Santa Cruz, CA, USA). Recombinant BMP4 protein (cat. no. 315-27; $30 \mathrm{ng} / \mathrm{ml}$ ) and recombinant murine IL-7 protein (cat. no. 217-17; 2 ng/ml) were both purchased from ProteinTech Group, Inc. Pyrrolidine dithiocarbamate (PDTC; cat. no. S1808; $30 \mathrm{ng} / \mathrm{ml}$ ), an inhibitor of NF- $\mathrm{B}$, was purchased from Beyotime Institute of Biotechnology (Wuhan, China).

Cell culture. IEC-6 IECs were purchased from the American Type Culture Collection (Manassas, VA, USA) and were grown in Dulbecco's modified Eagle's medium (Hyclone, Logan, UT, USA) supplemented with $10 \%$ fetal bovine serum (FBS; Gibco; Thermo Fisher Scientific, Carlsbad, CA, USA), 100 IU/ml penicillin, and $100 \mathrm{mg} / \mathrm{ml}$ streptomycin. IEC-6 cells were cultured at $37^{\circ} \mathrm{C}$ under normoxic $\left(5 \% \mathrm{CO}_{2}\right.$ and $\left.20 \% \mathrm{O}_{2}\right)$ conditions (Thermo Fisher Scientific, Inc., Waltham, MA, USA). For the western blot analysis, IL-7 was added to the medium for $6 \mathrm{~h}$.

Western blot analysis. The cells were washed twice with phosphate-buffered saline (PBS) prior to lysis in cold RIPA buffer [50 mM Tris, $150 \mathrm{mM} \mathrm{NaCl,} \mathrm{1 \%} \mathrm{Triton} \mathrm{X-100,} \mathrm{1 \%} \mathrm{sodium}$ deoxycholate, $0.1 \%$ sodium dodecyl sulfate (SDS) and $2 \mathrm{mM}$ sodium pyrophosphate]. The samples were then mixed with loading buffer and boiled for $5 \mathrm{~min}$ prior to electrophoresis. The proteins were loaded onto $8-10 \%$ SDS-PAGE gels and were subjected to electrophoresis at $100 \mathrm{~V}$ for $2 \mathrm{~h}$. After electrophoresis, the proteins were electroblotted onto nitrocellulose membranes at $200 \mathrm{~mA}$ for $2 \mathrm{~h}$. Non-specific binding was blocked by incubation in Tris-buffered saline (TBS) with $0.1 \%$ Tween-20 (TBS-T) and 5\% skimmed milk. The transferred membranes were incubated overnight at $4{ }^{\circ} \mathrm{C}$ with the following primary antibodies: Anti-BMP4 (1:500), anti-BMPRIA (1:200) and anti-GAPDH (1:5,000). After washing three times in TBS-T, the membranes were incubated with anti-rabbit IgG (cat. no. BA1001; Zhongshan Bio-Tech Co., Ltd., Beijing, China) conjugated to horseradish peroxidase 
at a dilution of 1:3,000 in TBS-T containing 5\% skimmed milk for $1 \mathrm{~h}$ at $37^{\circ} \mathrm{C}$. After three additional washes in TBS-T, the signals were visualized with the SuperSignal West Pico Trial kit (Pierce Biotechnology, Inc., Rockford, IL, USA) and detected with Image Station 4000R (Kodak, Rochester, NY, USA).

Animal experiments. Male C57BL/6 pathogen-free mice, aged 6-8 weeks (weight, 20-30 g), were purchased from the Laboratory Animal Center of the Third Military Medical University (Chongqing, China), and maintained in a temperature-, humidity- and light-controlled environment. The mice were randomly assigned to one of two groups ( $n=12 /$ group), the first of which was the I/R group. Following intraperitoneal anesthesia with $40 \mathrm{mg} / \mathrm{kg}$ pentobarbital, the abdomen was opened at the midline, and the superior mesenteric artery was occluded for $30 \mathrm{~min}$ using non-traumatic vascular clamps, followed by predefined times of reperfusion. The second group was the sham group, which included animals that were subjected to anesthesia and laparotomy without ischemia. All mice were sacrificed after $6 \mathrm{~h}$ by $\mathrm{CO}_{2}$ asphyxiation. The jejunal part of the small intestine was cut along the longitudinal axis, washed in physiological saline, and immediately frozen in liquid nitrogen and stored at $-70^{\circ} \mathrm{C}$ until use. The present study was approved by the Ethics Committee of Xinqiao Hospital, the Third Military Medical University. All animals were handled according to the guidelines for the Care and Use of Laboratory Animals (NIH publication no. 85-23, revised 1996).

Immunofluorescence analysis. In the present study, $10-\mu \mathrm{m}$ frozen sections were cut from the jejunum and were fixed onto slides. After fixation in $4 \%$ formaldehyde for $20 \mathrm{~min}$, the sections were incubated in $3 \% \mathrm{H}_{2} \mathrm{O}_{2}$ for $30 \mathrm{~min}$ to quench endogenous peroxidase activity. Non-specific binding was blocked with $5 \%$ bovine serum albumin (BSA) in PBS for $30 \mathrm{~min}$ at room temperature. The sections were then incubated overnight at $4^{\circ} \mathrm{C}$ in $3 \%$ BSA in PBS with the following primary antibodies: Anti-BMP4 and anti-IL-7, at a dilution of 1:50. The sections were washed three times with BSA in PBS and were incubated with Alexa 488-conjugated goat anti-rabbit antibody for $1 \mathrm{~h}$ at RT. After the nuclei were stained with DAPI, images were captured and analyzed with a Leica TCSSP confocal imaging system (Leica, Heidelberg, Germany).

Isolation of IELs from the small intestine. The isolation of IELs was performed according to the protocol of Mosley and Klein (28). Briefly, the small bowel was placed in RPMI-1640 tissue culture media supplemented with $10 \%$ FBS (both from Gibco; Thermo Fisher Scientific). The sections were cut into 5 - $\mathrm{mm}$ pieces, washed in an extraction buffer, and incubated in the same buffer with continuous brisk stirring at $37^{\circ} \mathrm{C}$ for $25 \mathrm{~min}$. The supernatant was filtered rapidly through a glass wool column. After centrifugation, the pellets were purified in 40\% isotonic Percoll (GE Healthcare Biosciences, Pittsburgh, PA, USA) and reconstituted in RPMI tissue culture media. The purity of the IELs was $>95 \%$, as assessed by trypan blue exclusion staining. Isolated IELs were counted with a Neubauer hemocytometer (Reichert Technologies, Buffalo, NY, USA).
IEL cell culture. IELs were isolated from the small intestine and grown in RPMI-1640 supplemented with 10\% FBS, $100 \mathrm{IU} / \mathrm{ml}$ penicillin and $100 \mathrm{mg} / \mathrm{ml}$ streptomycin. The IELs were cultured at $37^{\circ} \mathrm{C}$ under normoxic $\left(5 \% \mathrm{CO}_{2}\right.$ and $\left.20 \% \mathrm{O}_{2}\right)$ conditions (Thermo Fisher Scientific, Inc.), and the viability of the IELs automatically decreased under culture without interference. For flow cytometry, BMP4, NOGGIN, PDTC and IL-7 were added to the medium for $6 \mathrm{~h}$.

Flow cytometric analysis. The IEL phenotype was assessed with fluorescent antibody staining detected by flow cytometry. The following anti-mouse monoclonal antibodies were used: CD45-APC, BMPRIA-FITC, BMPRIB-FITC and CD127-Alexa Fluor 488. Isotype-matched, irrelevant antibodies were used as negative controls. The apoptotic ratios for the IELs in the different groups were measured by flow cytometry according to the manufacturer's instructions. Double staining for FITC-Annexin V binding and cellular DNA using propidium iodide were performed as described in the manufacturer's protocol. The acquisition and analysis were performed with MoFlo (Beckman Coulter, Brea, CA, USA).

Reverse trancsription-polymerase chain reaction (RT-PCR) analysis. Total RNA was isolated with TRIzol reagent (Takara Biotechnology Co., Ltd., Dalian, China). Single-stranded cDNA was synthesized with Moloney murine leukemia virus reverse transcriptase (Takara Biotechnology Co., Ltd.) and then used for PCR analysis. RT-PCR was performed with a SYBR PrimeScript RT kit according to the manufacturer's instructions (Takara Biotechnology Co., Ltd.). Amplifications were performed under the following conditions: $94^{\circ} \mathrm{C}$ for $5 \mathrm{~min}$, followed by 35 cycles at $94^{\circ} \mathrm{C}$ for $30 \mathrm{sec}, 59^{\circ} \mathrm{C}$ for $30 \mathrm{sec}$, and $72^{\circ} \mathrm{C}$ for $30 \mathrm{sec}$, followed by $72^{\circ} \mathrm{C}$ for $10 \mathrm{~min}$ in a PCR System 7500 (Applied Biosystems, Carlsbad, CA, USA). The following PCR primers were used: BMPRIA forward, 5'-CTTATTCTG CTGCTTGTGGTC-3' and reverse, 5'-AGCGGTTAGACA CGATTGG-3'; BMPRIB forward, 5'-AGGGTCAGATTTTCA ATGTCG-3' and reverse, 5'-GAGGTCGGGCTTCTTGTCT-3'; BMPRII forward, 5'-GATACAGAATGTTGACAGGAGACA GG-3' and reverse, 5'-GGAAATTGCAGGTTTGTAATGATC TC-3'; ActRIA forward, 5'-GGTTCCCAATGACCCAAG TTT-3' and reverse, 5'-CGAGCGAGGTTAGGGTGGTT-3'; p-NF- $\kappa$ B forward, 5'-CCTCGGGACAAACAGCCTC-3' and reverse, 5'-CACGGCGCG CTAAAGTAAAG-3'; IKb forward, 5'-CСТCACCCT TCCCCAATAAT-3' and reverse, 5'-GTG TGAATGGTGCCTGTGAC-3'; $\beta$-actin forward, 5'-ACCGTG AAAAGATGACCCAGATC-3' and reverse, 5'-GCCACAGGA TTCCATACCCAG-3'; RT-qPCR products were directly loaded onto non-denaturing 2\% agarose gels, stained with SYBR Safe (Invitrogen Life Technologies; Thermo Fisher Scientific, Carlsbad, CA, USA), and visualized under UV transillumination. The specificity of the primers was determined by sequencing the amplification products.

Statistical analysis. Statistical analyses were performed with SPSS 13.0 statistical software (SPSS Inc., Chicago, IL, USA). All data are expressed as the means \pm standard deviation. The results were analyzed using analysis of variance. Statistical significance was defined as $\mathrm{P}<0.05$. 
A

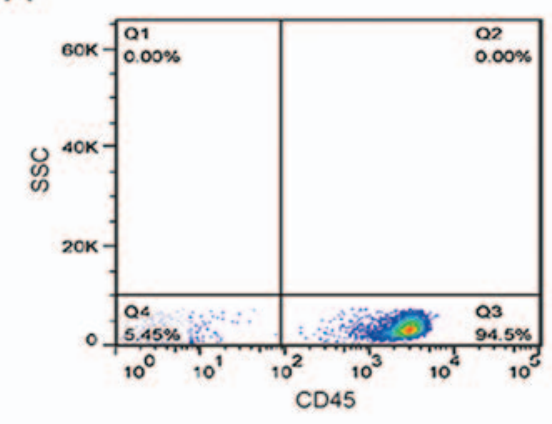

B

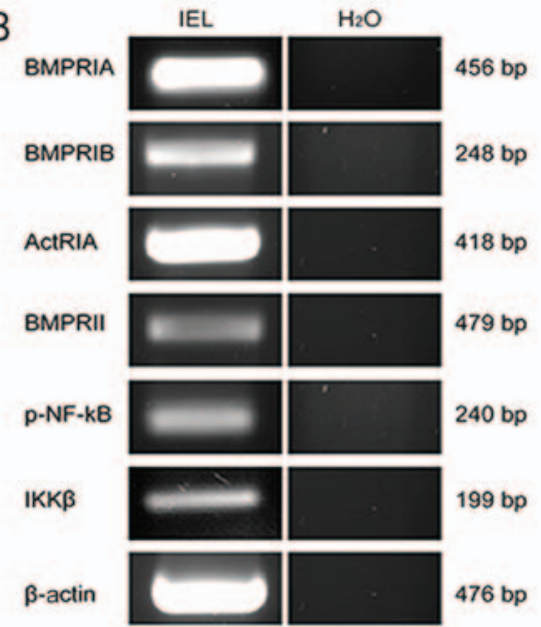

C
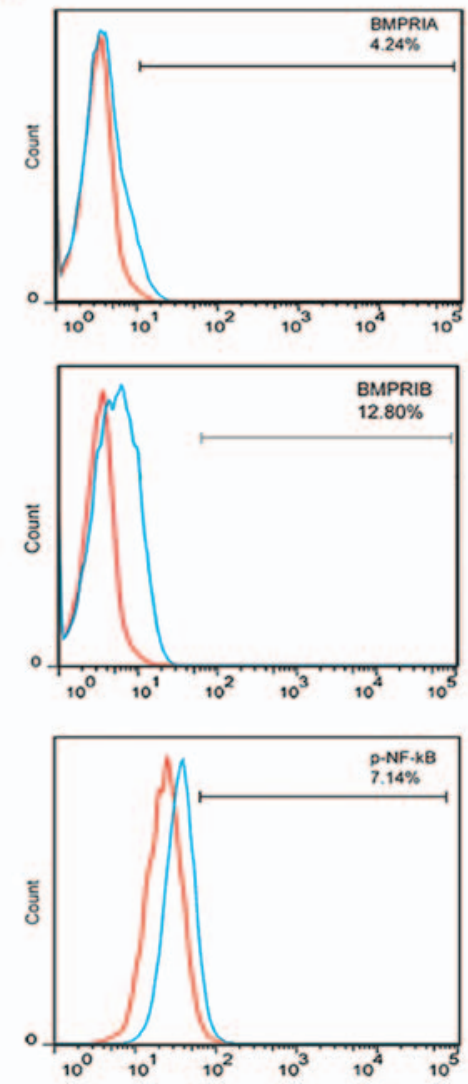

Figure 1. Intraepithelial lymphocytes (IELs) express bone morphogenetic protein (BMP) signaling pathway proteins. (A) Flow cytometric analysis of the purity of IELs that were isolated from the small intestine of mice. (B) Reverse transcription-polymerase chain reaction analysis of the expression of different components of the BMP signaling pathway in isolated IELs. Band sizes are indicated. $\mathrm{H}_{2} \mathrm{O}$ served as the negative control. (C) Surface expression of type I BMP receptors and phosphorylated nuclear factor (NF)- $\kappa \mathrm{B}$ in IELs. The percentage of positive cells are shown in each histogram. Red curves indicate background staining. The results are representative of three independent experiments.

\section{Results}

The BMP signaling pathway is functionally active in IELs. It has been previously reported that IEC dysfunction induced by BMP2/4 activates NF- $\mathrm{KB}$ signaling following I/R (12). In a similar manner, the inhibition of $\mathrm{CD}^{+} 4^{+}$progenitor cell differentiation under stimulation of the BMP2/4 signaling pathway has also been demonstrated (15). To determine whether BMP4 signaling also activates NF- $\mathrm{B}$ signaling in IELs, it was first demonstrated by flow cytometry that the purity of IELs isolated from the small intestine of mice reached $94.5 \%$, as shown in Fig. 1A. RT-PCR analysis demonstrated that IELs expressed three type I BMP receptors (BMPRIA, BaMPRIB and ActRIA), as well as one type II BMP receptor (BMPRII). Similarly, IELs expressed specific RNA for $\mathrm{p}-\mathrm{NF}-\kappa \mathrm{B}(\mathrm{IKK} \beta)$, as shown in Fig. 1B. The flow cytometric analysis revealed that the IELs expressed BMPRIA (4.24 $\pm 0.37 \%)$, BMPRIB $(12.8 \pm 0.67 \%)$, and phosphorylated NF- $\kappa$ B (P65) (7.14 $\pm 1.36 \%)$, as shown in Fig. 1C. Therefore, it may be hypothesized that BMP binds to BMP receptors and activates $\mathrm{NF}-\kappa \mathrm{B}$ signaling in IELs of the small intestine.

$I / R$ induces an increase the expression of BMP4 in IECs and upregulates BMP receptors and the phosphorylation of $N F-\kappa B$ in IELs. A previous study revealed more severe destruction of the intestinal morphology and some changes in protein secretion $6 \mathrm{~h}$ after I/R (29); moreover, the expression of the BMP4 protein was determined in IECs. The protein level of BMP4 in IECs was analyzed by immunofluorescence in the I/R group compared with the sham group, and the expression level of BMP4 was found to be markedly increased in IECs, as shown in Fig. 2A. Moreover, it was recently reported that I/R significantly altered IEL-derived cytokine expression in IELs (7). To better understand the changes in BMP receptors and $\mathrm{NF}-\kappa \mathrm{B}$ signaling in IELs following $\mathrm{I} / \mathrm{R}$, flow cytometry was performed and it demonstrated that the expression of BMPRIA, BMPRIB and phosphorylated $\mathrm{NF}-\kappa \mathrm{B}$ increased following I/R (BMPRIA, 12.66 $\pm 0.91 \%$; BMPRIB, $16.70 \pm 2.22 \%$; and p-NF- $\mathrm{BB}, 8.56 \pm 2.87 \%$ ), as shown in Fig. 2B. These data suggest that $\mathrm{I} / \mathrm{R}$ induces expression of IEC-derived BMP4 and activation of NF- $\kappa \mathrm{B}$ signaling in IELs.

Exogenous BMP4 regulates the $N F-\kappa B$ signaling pathway in IELs. The primary BMP receptors include two type I receptors (BMPRIA and BMPRIB) and one type II receptor (BMPRII). Typically, BMP4 binds to BMPRIA and BMPRIB, both of which have a high-affinity binding site for BMP4 (9). To determine whether the activation of $\mathrm{NF}-\kappa \mathrm{B}$ signaling in IELs involves IEC-derived BMP4, IELs from the small intestines of mice were isolated and cultured. It was observed that the protein levels of BMPRIA, BMPRIB and phosphorylated NF- $\mathrm{B}$ were highly 
A

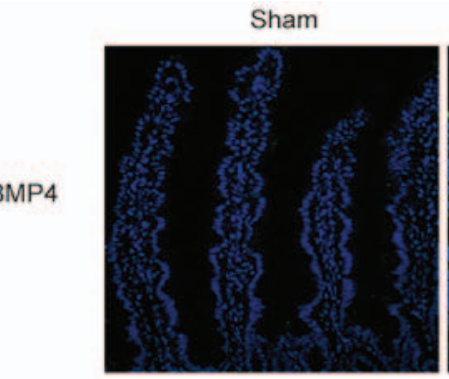

B
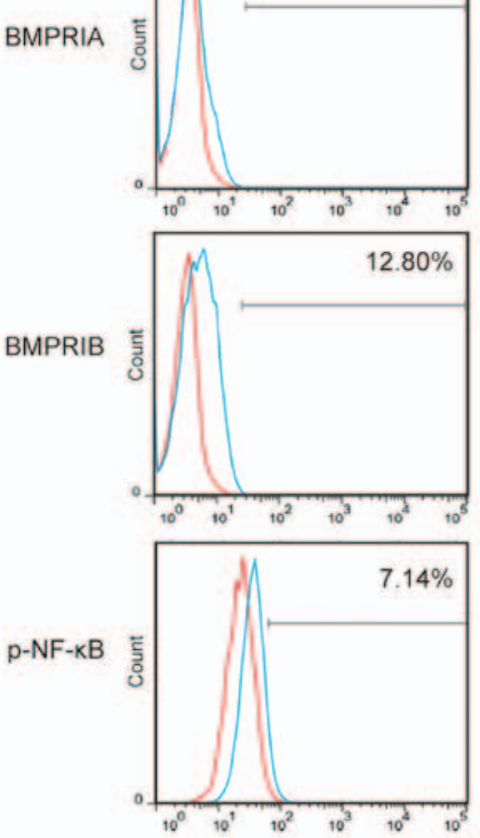

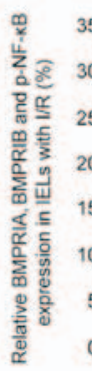

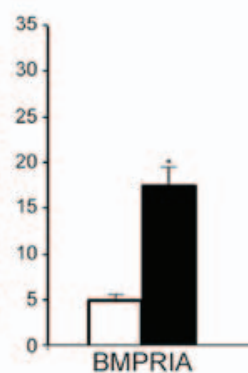

BMPRIA

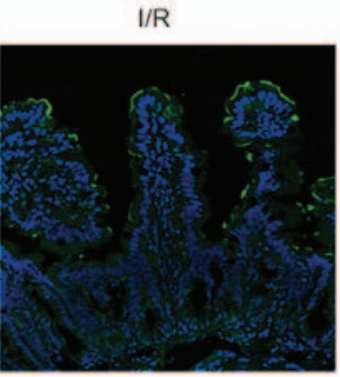

$17.50 \%$
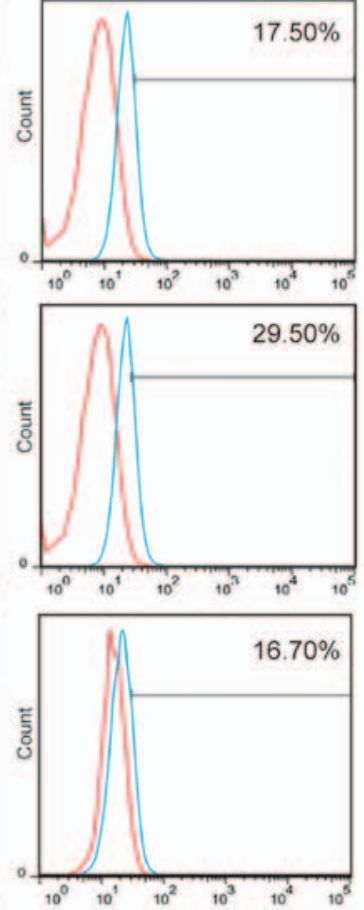

$6.70 \%$

Figure 2. The bone morphogenetic protein (BMP) signaling pathway is activated in intestinal epithelial cells and intraepithelial lymphocytes (IELs) following ischemia/reperfusion (I/R). (A) The level of BMP4 protein (red) expression significantly increased in the mid-to-distal villus region after $6 \mathrm{~h}$ of I/R, according to immunofluorescence staining. (B) The expression levels of the type I BMP receptor and phosphorylated nuclear factor (p-NF)- $\mathrm{B}$ were both significantly increased after $6 \mathrm{~h}$ of $\mathrm{I} / \mathrm{R}$ in IELs. ${ }^{*} \mathrm{P}<0.05,3-4 \mathrm{mice} /$ group; the results are representative of three independent experiments.

upregulated in IELs that were cultured in the presence of BMP4 $(30 \mathrm{ng} / \mathrm{ml})$, as assessed by flow cytometry (BMPRIA, $9.88 \pm 0.56 \%$; BMPRIB, $15.00 \pm 1.42 \%$; and p-NF-кB, $11.33 \pm 1.45 \%$ ). However, this effect was abolished by the BMP-specific antagonist NOGGIN (30 ng/ml), as shown in Fig. 3. Therefore, it is hypothesized that $\mathrm{I} / \mathrm{R}$ induces the activation of NF- $\mathrm{kB}$ signaling in IELs, possibly through IEC-derived BMP4.

$B M P 4 / N F-\kappa B$ signaling enhances the apoptosis of IELs cells. The effects of BMP4 on apoptosis of IELs were next evaluated following addition of exogenous recombinant BMP4 to the IEL cultures. Although the viability of the IELs decreased from 94.5 to $45 \%$ under without interference cultured, it was also observed that BMP4 induces IELs to undergo apoptosis $(13.20 \pm 2.25 \%)$. Activation of NF-kB in IELs by IEC-derived BMP4 $(30 \mathrm{ng} / \mathrm{ml})$ was observed. The blockade of BMP activity by the BMP antagonist NOGGIN (30 ng/ml), or by PDTC (30 $\mathrm{ng} / \mathrm{ml})$, resulted in a marked decrease in IEL apoptosis, as shown in Fig. 4. Therefore, these results strongly suggest that IEC-derived BMP4 activates NF- $\mathrm{kB}$ signaling in IELs, which leads to enhanced IEL apoptosis.

$I / R$ induces a decrease the expression of IL-7 in IECs and downregulates the expression of IL-7Ra/CDI27 and phosphorylated STAT5 in IELs. IEC-derived IL-7 plays a key role in the regulation of the development and homeostasis of neighboring IELs. IL-7 was also shown to significantly affect the phenotype and function of IELs, and caused an increase in the number of IELs (30). In a previous study, an decrease in IL-7 expression was confirmed in an intestinal I/R mouse model (31). In addition, by immunofluorescence analysis, a decreased expression of IL-7 in the cytoplasm of IECs after I/R was also confirmed compared with sham animals. Moreover, it has been reported that IL-7R $\alpha / C D 127$ may induce the phosphorylation of STAT5, which acts to maintain T-cell homeostasis and prevents the progression of inflammation. To better understand CD127 and the changes in phosphorylation of STAT5 in IELs after I/R, flow cytometric analysis was performed and revealed that CD127 expression and the phosphorylation of STAT5 decreased after I/R (CD127, 12.87 $\pm 1.32 \%$; and p-STAT5, $6.48 \pm 1.23 \%$ ), as shown in Fig. 5. These data suggest that the IL-7/CD127 signaling pathway is inhibited in IECs after I/R, further aggravating the deterioration of intestinal barrier function.

IL-7 inhibits BMP4, which induces the apoptosis of IELs. It is a known fact that the interaction between BMP4 and IL-7 maintains the balance of proliferation and differentiation in $\mathrm{CD}^{+}{ }^{+}$cells. To establish whether the interaction between BMP4 and IL-7 regulates the number of IELs, exogenous BMP4 (30 ng/ml) and IL-7 $(2 \mathrm{ng} / \mathrm{ml})$ proteins were added to cultured IELs for $6 \mathrm{~h}$. Flow cytometry demonstrated that treatment with IL-7 reduced the extent of apoptosis of IELs $(11.1 \pm 0.93 \%)$, and enhanced the apoptosis of IELs in the presence of BMP4 (11.8 $\pm 0.47 \%)$. Of note, no difference in the apoptosis of IELs in the presence of BMP4 combined with IL-7 stimulation was observed compared with the control group, as shown in Fig. 6. These results indicate that IEC-derived IL-7 signaling promotes the survival of IELs and neutralizes IEC-derived BMP4, which promotes the apoptosis of IELs following I/R.

IL-7 downregulates the BMP/NF- $\kappa B$ signaling pathway in IECs and in IELs. To determine how to delay the induction of IEL apoptosis by BMP4 in the presence of IL-7, the expression of BMP4 in IECs under IL-7 protein $(2 \mathrm{ng} / \mathrm{ml})$ stimulation was evaluated by western blot analysis. The expression level of BMP4 was found to be significantly decreased, as shown in Fig. 7A. Moreover, flow cytometry revealed that the expression of phosphorylated NF- $\mathrm{\kappa B}$ protein was downregulated as a result of IL-7 (2 ng/ml) stimulation in IELs in culture $(5.18 \pm 1.12 \%)$, 

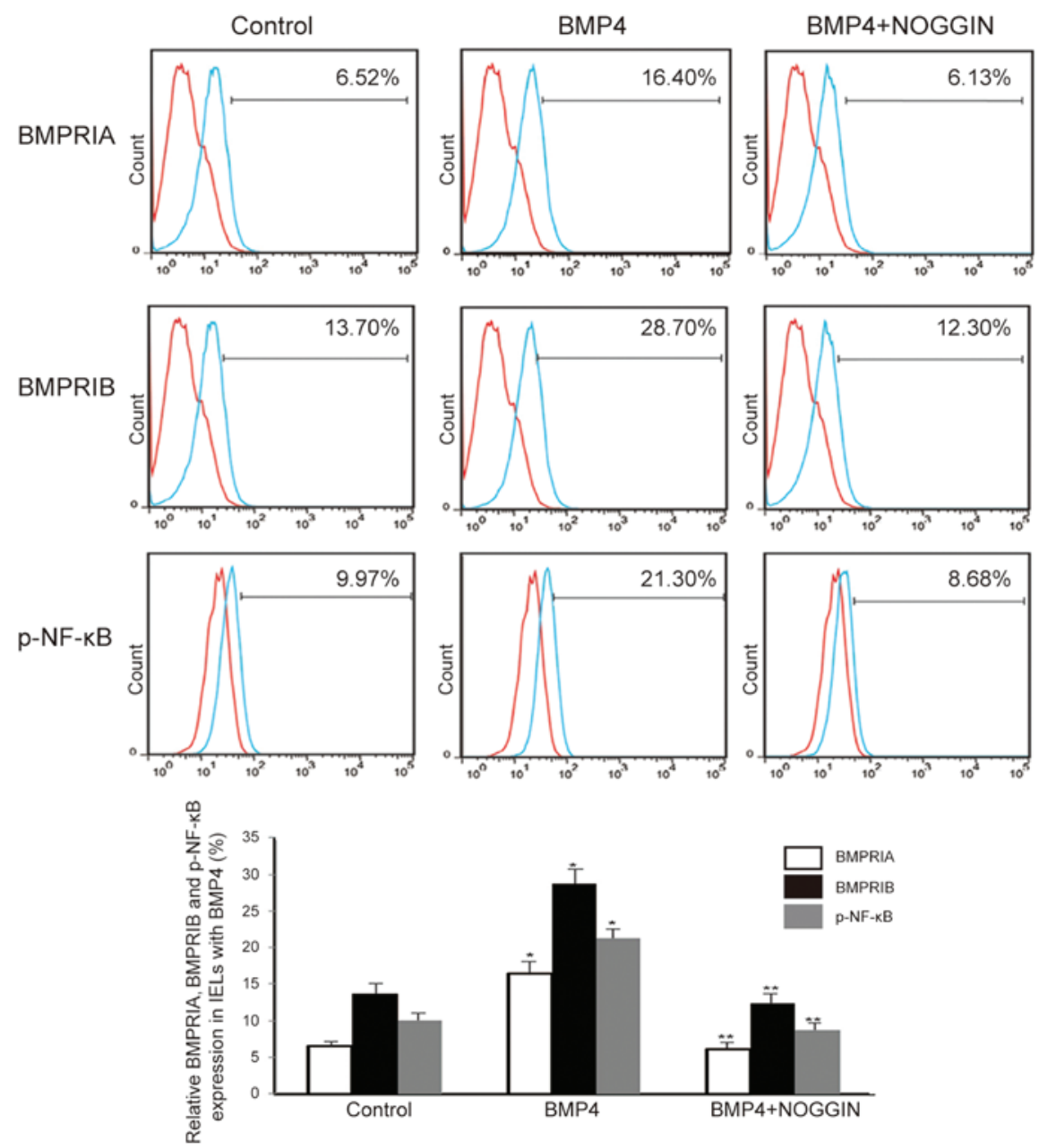

Figure 3. Activation of nuclear factor (NF)-kB signaling by bone morphogenetic protein (BMP)4 stimulation in intraepithelial lymphocytes (IELs). Flow cytometry determined the expression of the BMP type I receptor and phosphorylated NF-kB in IELs in culture. Following treatment with BMP4 for $6 \mathrm{~h}$, the expression of the BMP type I receptor and phosphorylated NF- $\mathrm{KB}$ was significantly increased compared with that in the control group. NOGGIN partially decreased the expression of the BMP type I receptor, as well as NF- $\mathrm{BB}$ transcriptional activity. The results are representative of three independent experiments. $\mathrm{P}<0.05$.
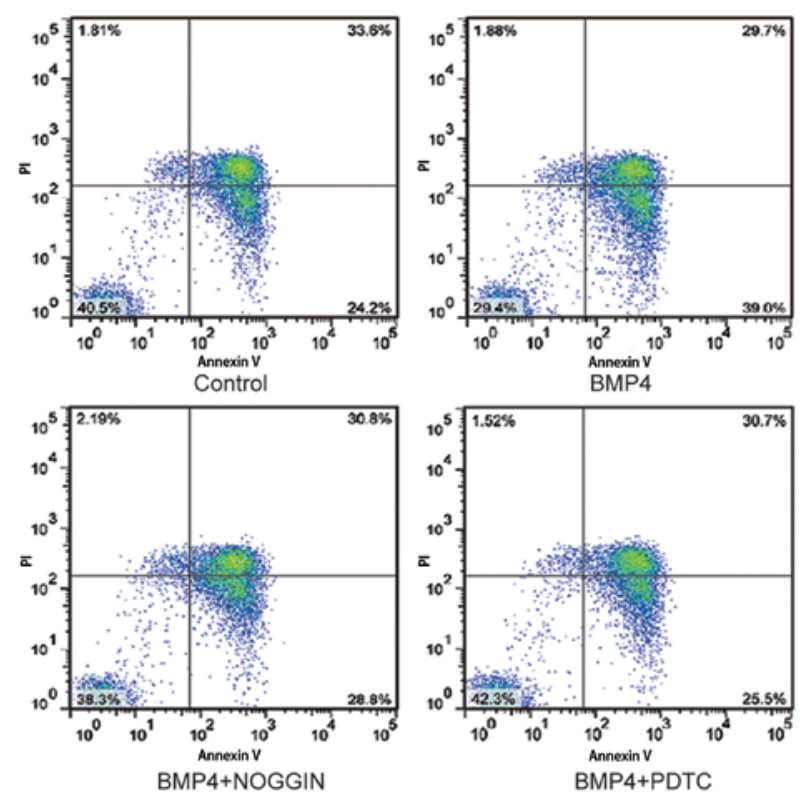

Figure 4. Bone morphogenetic protein (BMP)4 induces intraepithelial lymphocytes (IELs) to undergo apoptosis. Intestinal IELs were examined by flow cytometry for markers of apoptosis (FITC-Annexin $\mathrm{V}$ and PI). FITC-Annexin $\mathrm{V}^{+} / \mathrm{PI}^{+}$indicates late apoptosis, FITC-Annexin $\mathrm{V}^{+} / \mathrm{PI}^{-}$indicates early apoptosis, and FITC-Annexin $\mathrm{V}^{-} / \mathrm{PI}^{-}$indicates live cells. The extent of apoptosis of IELs after treatment with BMP4 for $6 \mathrm{~h}$ was then determined. The expression of FITC-Annexin $\mathrm{V}^{+} / \mathrm{PI}^{+}$IELs in the BMP4 group was significantly higher compared with that in the control group, but these effects were decreased by treatment with NOGGIN or pyrrolidine dithiocarbamate (PDTC). P<0.05, 3-4 mice/group; each experiment was repeated three times. 
A
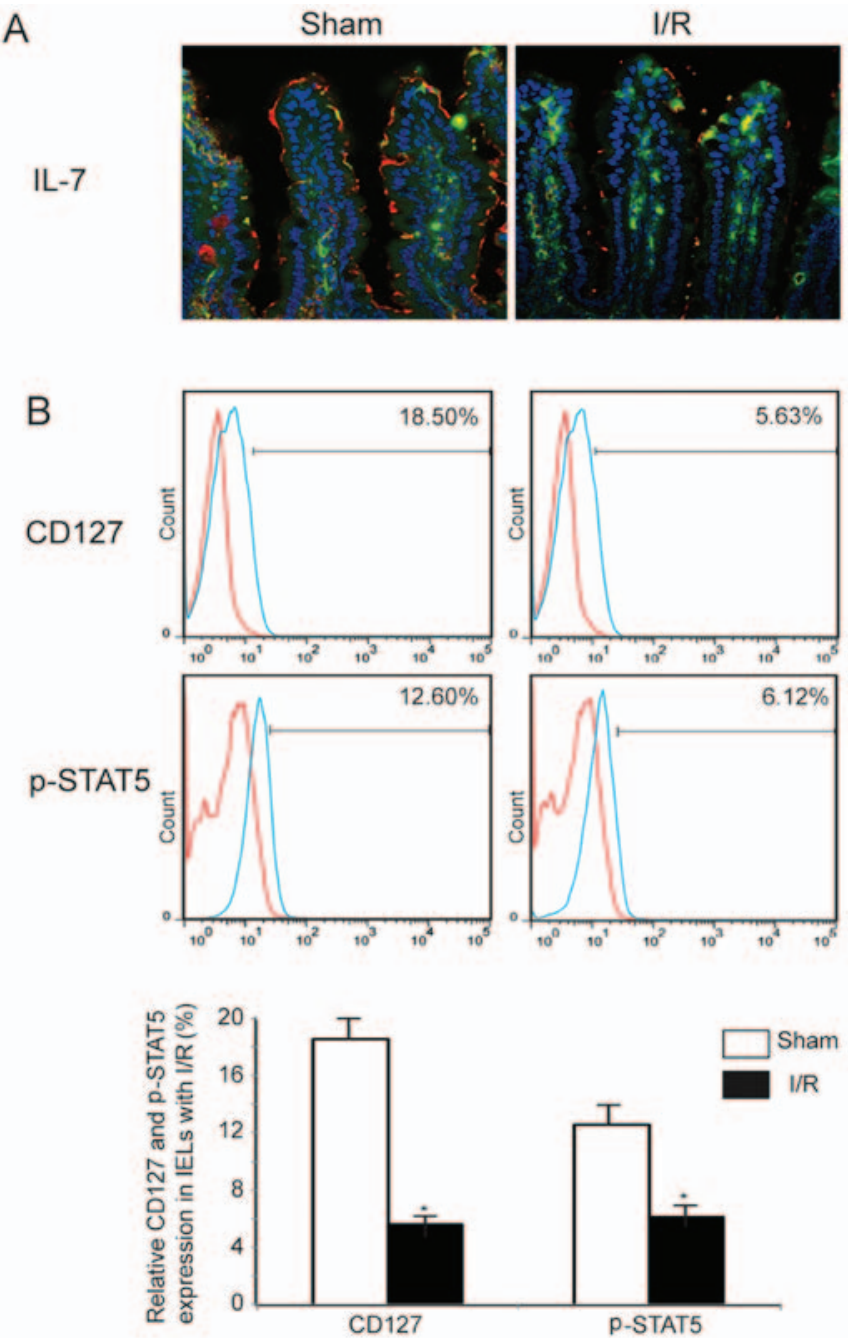

Figure 5. The interleukin (IL)-7/CD127 signaling pathway is downregulated in intestinal epithelial cells and intraepithelial lymphocytes (IELs) following ischemia/reperfusion (I/R). (A) The expression level of the IL-7 protein (green) was significantly decreased in the mid-to-distal villus region after $6 \mathrm{~h}$ of I/R according to immunofluorescence staining. (B) The expression levels of phosphorylated CD127 and STAT5 were both significantly downregulated after $6 \mathrm{~h}$ of I/R in IELs. ${ }^{*} \mathrm{P}<0.05,3-4$ mice/group; the results are representative of three independent experiments.

as shown in Fig. 7B. NF- $\mathrm{KB}$ signaling is known to increase the levels of inflammatory factors. It was hypothesized that IL-7 downregulates BMP4 and the phosphorylation of NF- $\mathrm{KB}$, thereby decreasing the expression of inflammatory factors to prevent the apoptosis of IELs.

BMP4 regulates the IL-7/CD127 signaling pathway in IECs and IELs. The majority of studies have demonstrated the role of IL-7 in T-cell homeostasis, in that CD127 induces STAT5 activation. The expression levels of CD127 were found to be highly downregulated in BMP4-treated CD34+ cells (15). Therefore, it was hypothesized that BMP4 promotes the apoptosis of IELs by downregulating CD127 in intestinal mucosal epithelial cells. Western blot analysis revealed that BMP4 $(30 \mathrm{ng} / \mathrm{ml})$ decreased the expression of the IL-7 protein in IECs, as shown in Fig. 8A. The expression level of CD127 dictates the levels of IL-7, which affect T-cell sensitivity (22). However, the expression of CD127 and the phosphorylation of STAT5 were downregulated in IELs that were cultured in the presence of BMP4 (30 ng/ml) (CD127, 7.30 $\pm 0.48 \%$; and p-STAT5, $4.77 \pm 1.77 \%$ ), but these effects were abolished with the application of NOGGIN (30 ng/ml), as shown in Fig. 8B. Therefore, it was hypothesized that BMP4 reduces IL-7 and IEL sensitivity through the downregulation of CD127 and the expression of phosphorylated STAT5, which would in turn negatively affect the number and function of IELs.

\section{Discussion}

The present study demonstrated that IEC-derived BMP4 activates the NF- $\mathrm{KB}$ signaling pathway to promote apoptosis of IELs following I/R. IL-7 exerts these inhibitory effects by counteracting the actions of BMP4. Previous studies have investigated the roles of the BMP proteins in early intestinal development and in the proliferation and differentiation of IECs $(32,33)$. We observed that the expression of BMP4 increases and that the expression of BMP receptors is also upregulated in IECs after hypoxia and I/R. BMP4 then activates NF- $\mathrm{KB}$ signaling, which leads to increased levels of inflammatory factors, such as TNF- $\alpha$ and IL-6. These factors can destroy the intestinal mucosal barrier, weakening its function (12). IEC-derived IL-7 plays a crucial role in the control of the development and homeostasis of neighboring IELs (23). Previous studies investigated the regulation of the population of progenitor cells in the human thymus and indicated that the balance between signals occurs as a result of the interplay between the BMP and IL-7 signaling pathways (15). However, the association between the interaction of the BMP and IL-7 signaling pathways and the regulation of IEL apoptosis following $\mathrm{I} / \mathrm{R}$ has rarely been reported.

The BMP signaling pathway plays a critical role in inflammatory reactions $(34,36)$. It was therefore hypothesized that the BMP signaling pathway contributes to the mechanisms that are involved in the promotion of apoptosis of IELs. The present study investigated the expression of BMP receptors (BMPRIA, BMPRIB, ActRIA and BMPRII) and phosphorylated NF- $\kappa$ B protein in IELs by RT-PCR and flow cytometry. Following I/R, IECs produce BMP4 abundantly, and IELs express increased levels of BMPRIA, BMPRIB and phosphorylated NF- $\kappa B$ proteins. Thus, the evidence suggests that BMP may activate NF- $\mathrm{BB}$ signaling in IELs after I/R. The addition of exogenous recombinant BMP4 to isolated and cultured IELs was found to directly activate NF- $\mathrm{KB}$ signaling, and this effect was weakened by the addition of the BMP-specific antagonist NOGGIN. It is known that an increase in the inflammatory cytokines IL- 6 and TNF- $\alpha$ is mediated via the NF- $\mathrm{KB}$ signaling pathway (12) and, thus, flow cytometry was used and revealed that the addition of exogenous recombinant BMP4 promoted IEL apoptosis. This effect was attenuated in part by either the BMP-specific antagonist NOGGIN or the NF- $\mathrm{BB}$ inhibitor PDTC. The present study provides new evidence that, following I/R, BMP4 derived from IECs may bind to the BMP receptors on IELs. The phosphorylation of NF- $\kappa \mathrm{B}$ allows for its translocation to the nucleus, so that it can trigger the transcription of genes that are involved in inflammatory cellular responses and other types of signaling (35). This, in turn, promotes the apoptosis of IELs. It was also recently confirmed that activating the 

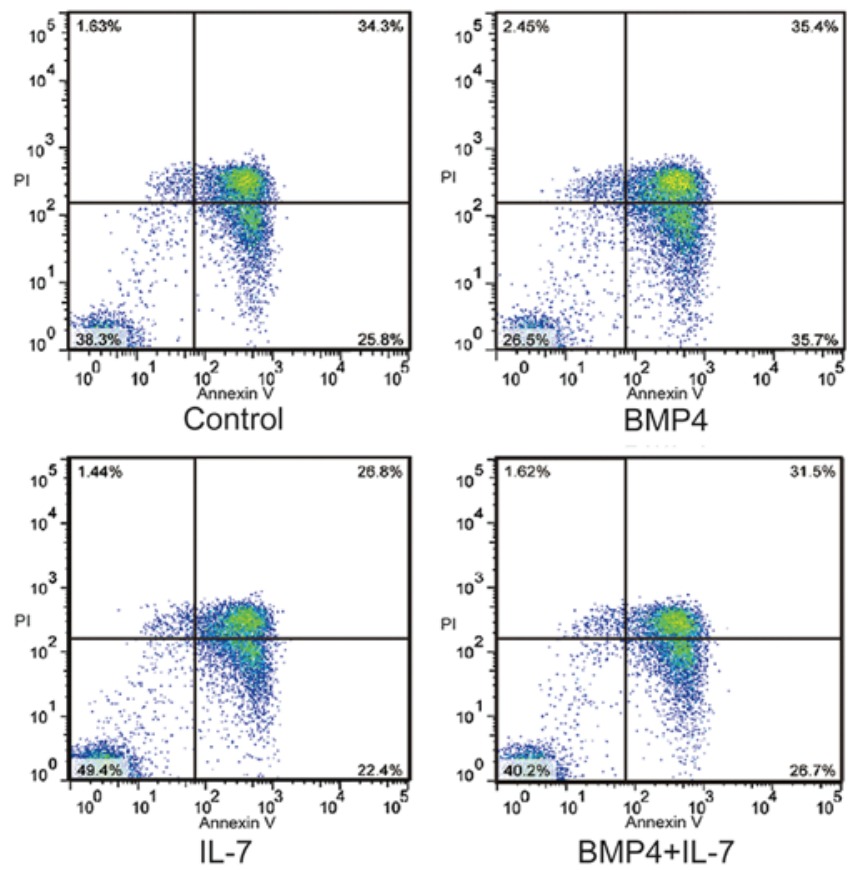

Figure 6. Inhibition of bone morphogenetic protein (BMP)4 induces the apoptosis of intraepithelial lymphocytes (IELs) that has been stimulated by interleukin (IL)-7. Flow cytometry and apoptosis markers (FITC-Annexin V and PI) were used to examine IEL apoptosis after treatment with BMP4, IL-7 or BMP4 + IL-7 for $6 \mathrm{~h}$. The expression of FITC-Annexin $\mathrm{V}^{+} / \mathrm{PI}^{+}$IELs in the IL-7 treatment group was significantly lower compared with that in the control group, whereas the expression of FITC-Annexin $\mathrm{V}^{+} / \mathrm{PI}^{+}$IELs in the BMP4 treatment group was significantly higher compared with that in the control group. However, the expression of FITC-Annexin $\mathrm{V}^{+} / \mathrm{PI}^{+}$IELs in the BMP4 + IL-7 treatment group exhibited no changes compared with the control group. Each experiment was repeated three times; 4-5 mice/group. $\mathrm{P}<0.05$.

A

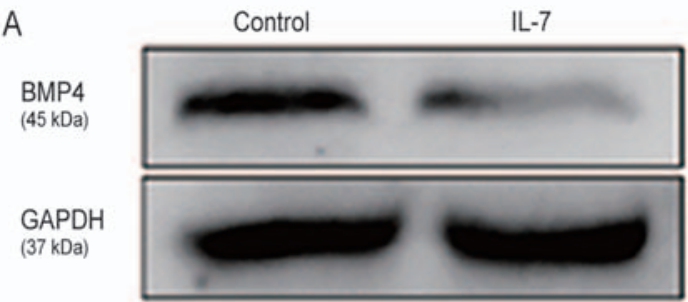

B

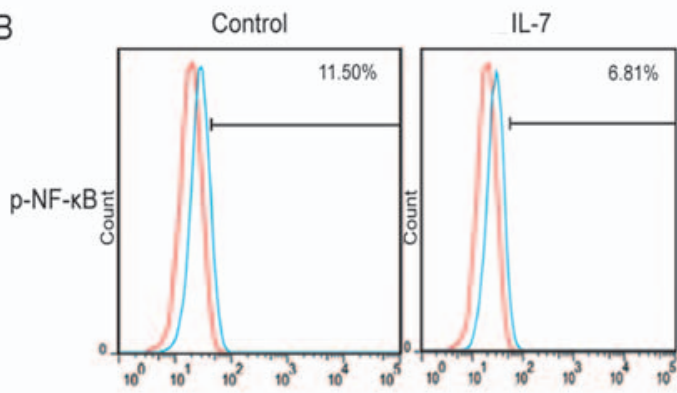

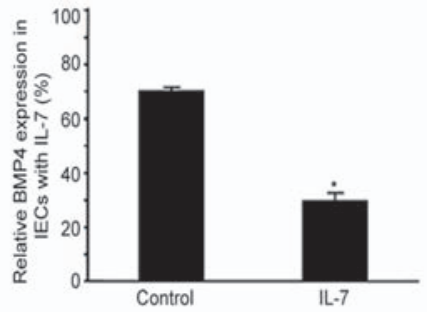

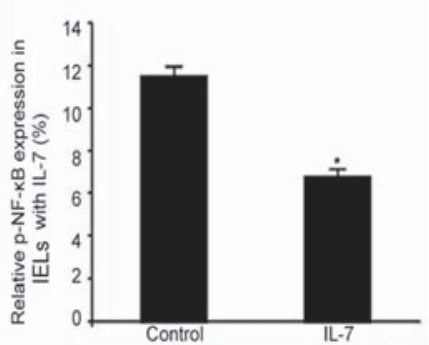

Figure 7. Interleukin (IL)-7 downregulates the bone morphogenetic protein (BMP) signaling pathway in intestinal epithelial cells (IECs) and intraepithelial lymphocytes (IELs). (A) Western blot analysis was used to determine the expression of BMP4 in IEC-6 cells following treatment with IL-7 for 6 h. The expression of BMP4 was significantly decreased compared with that in the control group. (B) Flow cytometry, was used to detect the phosphorylation of nuclear factor (NF)- $\kappa$ B following treatment with IL-7 for $6 \mathrm{~h}$. The expression of phosphorylated NF- $\mathrm{B}$ was significantly decreased compared with that in the control group. Each experiment was repeated three times; 4-5 mice/group. "P<0.05 vs. control. GAPDH, glyceraldehyde 3-phosphate dehydrogenase.

canonical Smad signaling pathway promotes the apoptosis of IELs after I/R. However, the underlying mechanism requires further elucidation.

The administration of IEC-derived IL-7 protein significantly affects the function and phenotype of IELs. The IL-7-induced increase in the number of IELs may be associated with the increased rate of IEL proliferation observed by immunofluorescence; however, the expression level of the IL-7 protein was found to be decreased in IECs following I/R for $6 \mathrm{~h}$. IL-7 affects T-cell sensitivity through the expression of CD127, and it is possible that the availability of IL-7 is limited in vivo $(36,37)$. Moreover, IL-7 induces the phosphorylation 

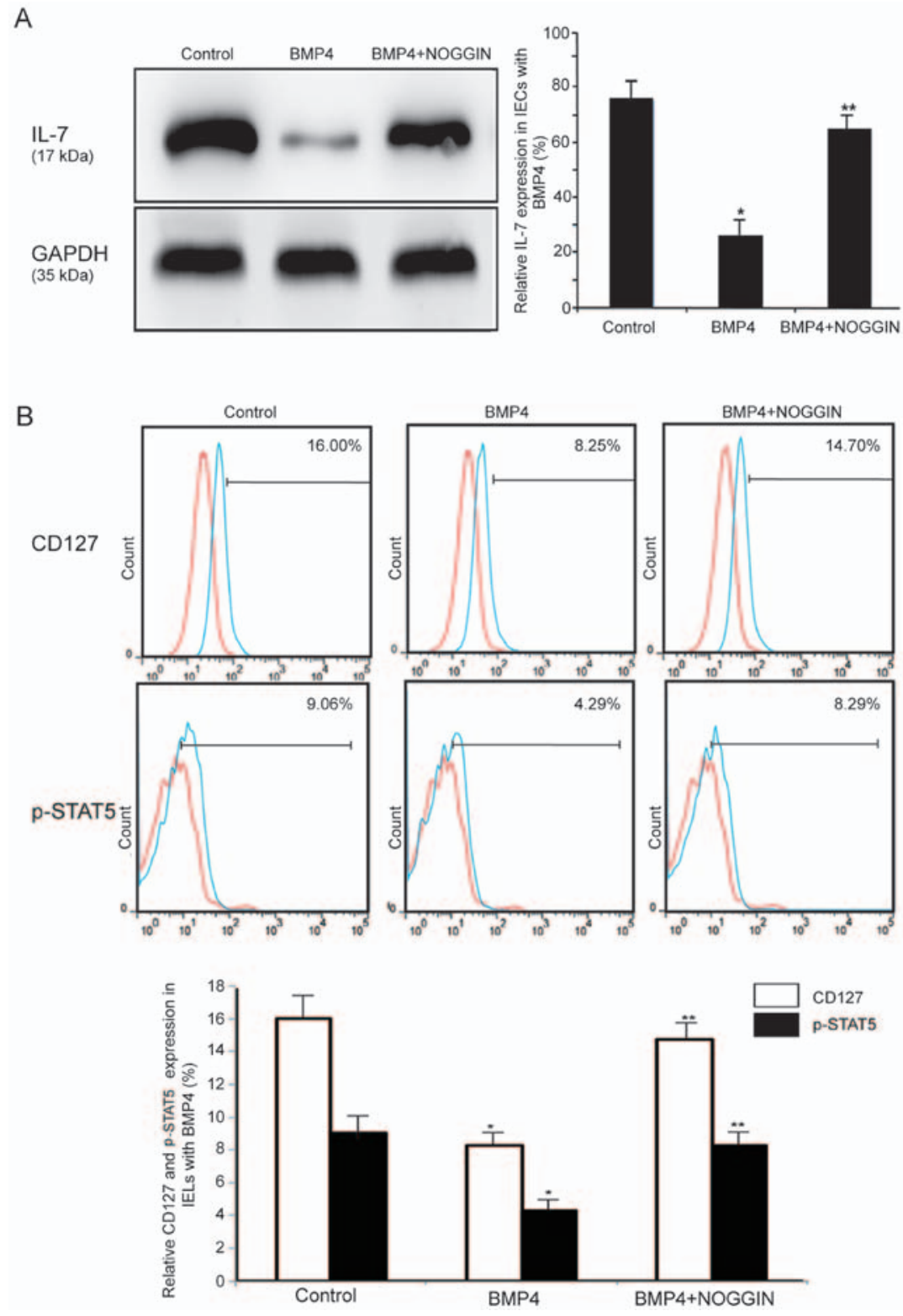

Figure 8. Bone morphogenetic protein (BMP)4 regulates the interleukin (IL)-7 $\alpha / C D 127$ signaling pathway in intestinal epithelial cells (IECs) and intraepithelial lymphocytes (IELs). (A) Western blot analysis determined the expression of IL-7 in IEC-6 cells following treatment with BMP4 for $6 \mathrm{~h}$. The IL-7 level was significantly decreased compared with that in the control group. (B) Flow cytometry, was used to detect the expression of CD127 and phosphorylated signal transducer and activator of transcription (STAT) 5 proteins following treatment with BMP4 for $6 \mathrm{~h}$. The levels of CD127 and phosphorylated STAT5 proteins were significantly decreased compared with those in the control group. Each experiment was repeated three times; $4-5$ mice/group. " $\mathrm{P}<0.05$ for control vs. treatment with BMP4 alone; ${ }^{* *} \mathrm{P}<0.05$ for control vs. the BMP4 + NOGGIN group. GAPDH, glyceraldehyde 3-phosphate dehydrogenase.

of STAT5, which then translocates into the nucleus where it controls the expression of target genes that are involved in the survival and proliferation of T cells (38). It has been reported that BMP4 exerts an inhibitory effect on proliferation and differentiation and, thus counteracts the functions of IL-7 in human intrathymic $\mathrm{CD} 34^{+}$precursor cells (15). These effects are mediated by BMP4-induced downregulation of CD127 expression in $\mathrm{CD}^{2} 4^{+}$precursor cells. CD127 deletion caused a $30 \%$ reduction in the numbers of $\mathrm{CD}^{+}$and $\mathrm{CD} 8^{+} \mathrm{T}$ cells, which confirms a key role for IL-7R in the maintenance of peripheral T-cell survival (39). More importantly, other data directly indicate that BMP4 downregulates the level of CD127 and p-STAT5 expression in IELs in culture, which leads to a reduction in the sensitivity of IELs to IL-7. Therefore, BMP4 induces a decrease in the number of IELs and weakens
IEL function. Based on these data, it may be inferred that IEC-derived BMP4 not only activates NF- $\kappa \mathrm{B}$ signaling to induce IEL apoptosis, but also downregulates CD127 and p-STAT5 protein expression to shorten the survival of IELs. IEC-derived IL-7 directly affects the number and function of IELs; furthermore, it was observed that IL-7 protein expression decreases following BMP4 stimulation. It may thus be hypothesized that the decreasing expression of IL-7 was associated with the increasing expression of BMP4 in IECs following I/R. The reasons for this finding are not clear and require confirmation in future experiments.

The protein level of BMP4 in IECs, as well as the phosphorylation of NF- $\mathrm{KB}$ in IELs, were found to be significantly downregulated in the presence of IL-7. The addition of exogenous IL-7 markedly reversed BMP4-induced apoptosis of 
IELs. As a result, it may be inferred that IL-7 exerts protective effects in terms of the number and function of IELs through the downregulation of deleterious factors that are triggered by the $\mathrm{BMP} / \mathrm{NF}-\kappa \mathrm{B}$ signaling pathways. This protective effect decreases IEL apoptosis after I/R, effectively preventing further deterioration of intestinal barrier function.

The regulation of $\mathrm{NF}-\kappa \mathrm{B}$ expression in developing $\mathrm{T}$ cells and the role of this pathway in selection and lineage determination is complex (16). Recent studies reported that basal nuclear $\mathrm{NF}-\kappa \mathrm{B}$ activity plays an important role in the transcription of CD127, which facilitates the responsiveness of naïve $T$ cells to the prosurvival effects of IL-7 and allows for T-cell persistence in vivo (40). Additionally, a developmental function has been reported for $\mathrm{NF}-\kappa \mathrm{B}$ signaling in the homeostatic maturation of new $\mathrm{T}$ cells via the regulation of IL-7R $\alpha$ expression (41). Our data revealed an increase the phosphorylation of $\mathrm{NF}-\kappa \mathrm{B}$ and decrease in IL-7/CD127 protein expression in IELs after $\mathrm{I} / \mathrm{R}$. However, whether there is an association between $\mathrm{NF}-\kappa \mathrm{B}$ and IL-7/CD127 remains unclear. Hence, it is recommended that the association between NF- $\mathrm{KB}$ and IL-7/CD127 is further investigated in a mouse model of $\mathrm{I} / \mathrm{R}$.

To the best of our knowledge, the present study is the first to report that BMP4 expression was increased in IECs and that IEC-derived BMP4 can directly activate NF- $\mathrm{BB}$ signaling and induce apoptosis of IELs following I/R. Additionally, IEC-derived IL-7 was shown to downregulate BMP4 signaling after I/R, which limits the extent of IEL apoptosis. This may result in the maintenance of the balance of the number of IELs and their function following I/R. All these effects indicate the importance of the interplay of BMP4 and IL-7 and the dialogue between IECs and IELs in the intergrity of the intestinal mucosal barrier.

\section{Acknowledgements}

The present study was supported by the National Natural Science Foundation of China (grant nos. NSFC 81071532 and 81370479 to C.J.Z.).

\section{Competing interests}

The authors declare that they have no competing interests.

\section{References}

1. Collard CD and Gelman S: Pathophysiology, clinical manifestations, and prevention of ischemia-reperfusion injury. Anesthesiology 94: 1133-1138, 2001

2. Grootjans J, Lenaerts K, Derikx JP, Matthijsen RA, de Bruïne AP, van Bijnen AA, van Dam RM, Dejong $\mathrm{CH}$ and Buurman WA Human intestinal ischemia-reperfusion-induced inflammation characterized: experiences from a new translational model. Am J Pathol 176: 2283-2291, 2010.

3. Andrade ME, Araújo RS, de Barros PA, Soares AD, Abrantes FA, Generoso SV, Fernandes SO and Cardoso VN: The role of immunomodulators on intestinal barrier homeostasis in experimental models. Clin Nutr 34: 1080-1087, 2015.

4. Andres SF, Simmons JG, Mah AT, Santoro MA, Van Landeghem L and Lund PK: Insulin receptor isoform switching in intestinal stem cells, progenitors, differentiated lineages and tumors: evidence that IR-B limits proliferation. J Cell Sci 126: 5645-5656, 2013.

5. Beagley KW, Fujihashi K, Lagoo AS, Lagoo-Deenadaylan S, Black CA, Murray AM, Sharmanov AT, Yamamoto M, McGhee JR, Elson CO, et al: Differences in intraepithelial lymphocyte $\mathrm{T}$ cell subsets isolated from murine small versus large intestine. J Immunol 154: 5611-5619, 1995.
6. Cheroutre H, Lambolez F and Mucida D: The light and dark sides of intestinal intraepithelial lymphocytes. Nat Rev Immunol 11: 445-456, 2011.

7. Qiu Y, Yu M, Yang Y, Sheng H, Wang W, Sun L, Chen G, Liu Y, Xiao W and Yang H: Disturbance of intraepithelial lymphocytes in a murine model of acute intestinal ischemia/reperfusion. J Mol Histol 45: 217-227, 2014.

8. Qiu Y and Yang H: Effects of intraepithelial lymphocyte-derived cytokines on intestinal mucosal barrier function. J Interferon Cytokine Res 33: 551-562, 2013.

9. Miyazono K, Kamiya Y and Morikawa M: Bone morphogenetic protein receptors and signal transduction. J Biochem 147: 35-51, 2010.

10. Core AB, Canali S and Babitt JL: Hemojuvelin and bone morphogenetic protein (BMP) signaling in iron homeostasis. Front Pharmacol 5: 104, 2014.

11. 11. Zhang C, Feng Y, Yang H, Koga $\mathrm{H}$ and Teitelbaum DH: The bone morphogenetic protein signaling pathway is upregulated in a mouse model of total parenteral nutrition. J Nutr 139: 1315-1321, 2009.

12. Chen K, Xie W, Luo B, Xiao W, Teitelbaum DH, Yang H, Zhang $\mathrm{K}$ and Zhang $\mathrm{C}$ : Intestinal mucosal barrier is injured by BMP2/4 via activation of NF- $\kappa$ B signals after ischemic reperfusion. Mediators Inflamm 2014: 901530, 2014.

13. Yoshioka Y, Ono M, Osaki M, Konishi I and Sakaguchi S: Differential effects of inhibition of bone morphogenic protein (BMP) signalling on T-cell activation and differentiation. Eur J Immunol 42: 749-759, 2012

14. Hager-Theodorides AL, Ross SE, Sahni H, Mishina Y, Furmanski AL and Crompton T: Direct BMP2/4 signaling through BMP receptor IA regulates fetal thymocyte progenitor homeostasis and differentiation to $\mathrm{CD} 4^{+} \mathrm{CD} 8^{+}$double-positive cell. Cell Cycle 13: 324-333, 2014.

15. Varas A, Sacedón R, Hidalgo L, Martínez VG, Valencia J, Cejalvo T, Zapata A, Hernández-López C and Vicente A: Interplay between BMP4 and IL-7 in human intrathymic precursor cells. Cell Cycle 8: 4119-4126, 2009.

16. Gerondakis S, Fulford TS, Messina NL and Grumont RJ: NF- $\kappa B$ control of T cell development. Nat Immunol 15: 15-25, 2014.

17. Fan Z, Jing H, Yao J, Li Y, Hu X, Shao H, Shen G, Pan J, Luo F and Tian X: The protective effects of curcumin on experimental acute liver lesion induced by intestinal ischemia-reperfusion through inhibiting the pathway of NF- $\mathrm{BB}$ in a rat model. Oxid Med Cell Longev 2014: 191624, 2014.

18. Kim GY, Hong C and Park JH: Seeing is believing: illuminating the source of in vivo interleukin-7. Immune Netw 11: 1-10, 2011.

19. Sprent J and Surh CD: Normal T cell homeostasis: the conversion of naive cells into memory-phenotype cells. Nat Immunol 12: 478-484, 2011.

20. Chetoui N, Boisvert M, Gendron S and Aoudjit F: Interleukin-7 promotes the survival of human $\mathrm{CD}^{+}$effector/memory $\mathrm{T}$ cells by up-regulating Bcl-2 proteins and activating the JAK/STAT signalling pathway. Immunology 130: 418-426, 2010.

21. Tal N, Shochat C, Geron I, Bercovich D and Izraeli S: Interleukin 7 and thymic stromal lymphopoietin: from immunity to leukemia. Cell Mol Life Sci 71: 365-378, 2014.

22. Carrette F and Surh CD: IL-7 signaling and CD127 receptor regulation in the control of T cell homeostasis. Semin Immunol 24: 209-217, 2012.

23. Monneret G, Villars-Méchin A, Demaret J, Foray AP and Venet F: Interleukin-7, a new immunoadjuvant for the treatment of septic shock. Med Sci (Paris) 30: 160-165, 2014 (In French).

24. Geiselhart LA, Humphries CA, Gregorio TA, Mou S, Subleski J and Komschlies KL: IL-7 administration alters the CD4:CD8 ratio, increases $\mathrm{T}$ cell numbers, and increases $\mathrm{T}$ cell function in the absence of activation. J Immunol 166: 3019-3027, 2001.

25. Cai YJ, Wang WS, Yang Y, Sun LH, Teitelbaum DH and Yang H: Up-regulation of intestinal epithelial cell derived IL-7 expression by keratinocyte growth factor through STAT1/IRF-1, IRF-2 pathway. PLoS One 8: e58647, 2013.

26. Yang $\mathrm{H}$, Gumucio DL and Teitelbaum DH: Intestinal specific overexpression of interleukin-7 attenuates the alternation of intestinal intraepithelial lymphocytes after total parenteral nutrition administration. Ann Surg 248: 849-856, 2008.

27. Shitara S, Hara T, Liang B, Wagatsuma K, Zuklys S, Holländer GA, Nakase H, Chiba T, Tani-ichi S and Ikuta K: IL-7 produced by thymic epithelial cells plays a major role in the development of thymocytes and TCR $\gamma \delta^{+}$intraepithelial lymphocytes. J Immunol 190: 6173-6179, 2013. 
28. Mosley RL and Klein JR: A rapid method for isolating murine intestine intraepithelial lymphocytes with high yield and purity. $\mathrm{J}$ Immunol Methods 156: 19-26, 1992.

29. Vollmar B and Menger MD: Intestinal ischemia/reperfusion: microcirculatory pathology and functional consequences. Langenbecks Arch Surg 396: 13-29, 2011.

30. Ji T, Xu C, Sun L, Yu M, Peng K, Qiu Y, Xiao W and Yang H: Aryl hydrocarbon receptor activation down-regulates IL-7 and reduces inflammation in a mouse model of DSS-induced colitis. Dig Dis Sci 60: 1958-1966, 2015.

31. Cai YJ, Wang WS, Liang HY, Sun LH, Teitelbaum DH and Yang H: Keratinocyte growth factor up-regulates interleukin-7 expression following intestinal ischemia/reperfusion in vitro and in vivo. Int J Clin Exp Pathol 5: 569-580, 2012.

32. Jain AP, Pundir S and Sharma A: Bone morphogenetic proteins: the anomalous molecules. J Indian Soc Periodontol 17: 583-586, 2013.

33. Bandyopadhyay A, Yadav PS and Prashar P: BMP signaling in development and diseases: a pharmacological perspective. Biochem Pharmacol 85: 857-864, 2013.

34. Bruun C, Christensen GL, Jacobsen ML, Kanstrup MB, Jensen PR, Fjordvang H, Mandrup-Poulsen T and Billestrup N: Inhibition of beta cell growth and function by bone morphogenetic proteins. Diabetologia 57: 2546-2554, 2014.

35. Yan R, Li Y, Zhang L, Xia N, Liu Q, Sun H and Guo H: Augmenter of liver regeneration attenuates inflammation of renal ischemia/reperfusion injury through the NF-kappa B pathway in rats. Int Urol Nephrol 47: 861-868, 2015.
36. Park JH, Yu Q, Erman B, Appelbaum JS, Montoya-Durango D, Grimes HL and Singer A: Suppression of IL7Ralpha transcription by IL-7 and other prosurvival cytokines: a novel mechanism for maximizing IL-7-dependent T cell survival. Immunity 21 : 289-302, 2004.

37. Henriques CM, Rino J, Nibbs RJ, Graham GJ and Barata JT: IL-7 induces rapid clathrin-mediated internalization and JAK3-dependent degradation of IL-7Ralpha in T cells. Blood 115: 3269-3277, 2010.

38. Jiang Q, Li WQ, Aiello FB, Mazzucchelli R, Asefa B, Khaled AR and Durum SK: Cell biology of IL-7, a key lymphotrophin. Cytokine Growth Factor Rev 16: 513-533, 2005.

39. Jacobs SR, Michalek RD and Rathmell JC: IL-7 is essential for homeostatic control of T cell metabolism in vivo. J Immunol 184: 3461-3469, 2010.

40. Miller ML, Mashayekhi M, Chen L, Zhou P, Liu X, Michelotti M, Tramontini Gunn N, Powers S, Zhu X, Evaristo C, et al: Basal $\mathrm{NF}-\kappa \mathrm{B}$ controls IL-7 responsiveness of quiescent naïve T cells. Proc Natl Acad Sci USA 111: 7397-7402, 2014.

41. Silva A, Cornish G, Ley SC and Seddon B: NF- $\kappa$ B signaling mediates homeostatic maturation of new T cells. Proc Natl Acad Sci USA 111: E846-E855, 2014.

This work is licensed under a Creative Commons Attribution-NonCommercial-NoDerivatives 4.0 International (CC BY-NC-ND 4.0) License. 